\title{
Inconsistent impacts of decomposer diversity on the stability of aboveground and belowground ecosystem functions
}

\author{
Nico Eisenhauer • Martin Schädler
}

Received: 4 December 2009/ Accepted: 6 September 2010/Published online: 28 September 2010

(C) The Author(s) 2010. This article is published with open access at Springerlink.com

\begin{abstract}
The intensive discussion on the importance of biodiversity for the stability of essential processes in ecosystems has prompted a multitude of studies since the middle of the last century. Nevertheless, research has been extremely biased by focusing on the producer level, while studies on the impacts of decomposer diversity on the stability of ecosystem functions are lacking. Here, we investigate the impacts of decomposer diversity on the stability (reliability) of three important aboveground and belowground ecosystem functions: primary productivity (shoot and root biomass), litter decomposition, and herbivore infestation. For this, we analyzed the results of three laboratory experiments manipulating decomposer diversity (1-3 species) in comparison to decomposer-free treatments in terms of variability of the measured variables. Decomposer diversity often significantly but inconsistently affected the stability of all aboveground and belowground ecosystem functions investigated in the present study.
\end{abstract}

Communicated by Roland Brandl.

N. Eisenhauer and M. Schädler contributed equally to this work.

N. Eisenhauer

J.F. Blumenbach Institute of Zoology and Anthropology, Georg-August-University Göttingen, Berliner Str. 28,

37073 Göttingen, Germany

Present Address:

N. Eisenhauer $(\bowtie)$

Department of Forest Resources, University of Minnesota,

1530 Cleveland Avenue N, St. Paul, MN 55108, USA

e-mail: nico.eisenhauer@web.de

M. Schädler

Department Community Ecology, UFZ,

Helmholtz-Centre for Environmental Research, UFZ,

Theodor-Lieser-Str. 4, 06120 Halle, Germany
While primary productivity was mainly destabilized, litter decomposition and aphid infestation were essentially stabilized by increasing decomposer diversity. However, impacts of decomposer diversity varied between plant community and fertility treatments. There was no general effect of the presence of decomposers on stability and no trend toward weaker effects in fertilized communities and legume communities. This indicates that impacts of decomposers are based on more than effects on nutrient availability. Although inconsistent impacts complicate the estimation of consequences of belowground diversity loss, underpinning mechanisms of the observed patterns are discussed. Impacts of decomposer diversity on the stability of essential ecosystem functions differed between plant communities of varying composition and fertility, implicating that human-induced changes of biodiversity and land-use management might have unpredictable effects on the processes mankind relies on. This study therefore points to the necessity of also considering soil feedback mechanisms in order to gain a comprehensive and holistic understanding of the impacts of current global change phenomena on the stability of essential ecosystem functions.

Keywords Above- and belowground interactions .

Belowground diversity - Diversity-stability relationship . Ecosystem reliability · Grassland

\section{Introduction}

Biodiversity is widely accepted as a key determinant driving the stability of ecosystems and their functions (McCann 2000). The current loss of biodiversity has thus prompted a considerable quantity of studies aiming to 
evaluate the consequences for mankind (e.g., Naeem and $\mathrm{Li}$ 1997; Yachi and Loreau 1999; Balvanera et al. 2006). Beginning with predictions by MacArthur (1955) and Elton (1958), biodiversity has been shown to govern various aspects of ecosystem stability, such as temporal stability (Tilman et al. 2006), spatial stability (Weigelt et al. 2008), resistance against perturbations (Mulder et al. 2001), resistance against invasions (Fargione and Tilman 2005), resilience (Tilman and Downing 1994), and reliability (Naeem and Li 1997).

Mechanisms underlying this positive diversity-stability relationship are manifold. First, diverse communities host a variety of life strategies that can respond differently to environmental perturbations and thus ensure ecosystem stability (Tilman et al. 2006). For instance, the variable densities of species populations may add up to a relatively constant overall productivity in more diverse communities, calling for the consideration of diversity effects on the respective level of organization (McCann 2000). Second, diverse communities are often characterized by complementary resource usage, both in time and space (Fargione and Tilman 2005; Tilman et al. 2006; Weigelt et al. 2008). Third, the increasing number of weak species interactions in diverse communities stabilizes community dynamics by dampening strong, potentially destabilizing consumerresource interactions (Berlow 1999).

Whilst early studies focussed on the feedback mechanisms between diversity and stability of primary producers, current research indicates a specific importance of interactions with higher trophic levels, such as that of decomposers, herbivores and predators, for the understanding of the observed patterns (Raffaelli et al. 2002; Brose 2008). Recent studies highlight the importance of belowground biota in structuring plant communities (De Deyn et al. 2003; Schädler et al. 2004; van der Heijden et al. 2008; Eisenhauer et al. 2010a, b). It seems to be evident that this influence may interfere with the relationship between plant community structure and ecosystem processes. For instance, animal ecosystem engineers have been shown to modulate the diversity-invasibility relationship in grasslands (Eisenhauer and Scheu 2008; Eisenhauer et al. 2008). This influence of the consumer level is further supported by the increasing recognition of the importance of diversity and complexity within these groups for ecosystem functions. Bardgett and Cook (1998) hypothesized that soil biodiversity influences the stability of soil ecosystems in terms of structure and functioning; however, experimental evidence is still scarce. So far, the available data suggest a high variability of effects both in magnitude and direction for soil microorganisms (van der Heijden et al. 2008) and soil animals (Mikola et al. 2002). The current loss of biodiversity in the belowground subsystem (reviewed in Hooper et al. 2000), however, calls for a comprehensive knowledge on the consequences of the decrease in soil biodiversity for ecosystem functions and stability (Wolters 2001). Especially, we lack an understanding of the impacts of decomposer diversity on the stability of ecosystem functions.

Soil biota is an important determinant of cycling and transformation of matter and energy, and their contribution for ecosystem and community stability is therefore beyond doubt. The high diversity of soil biota is reflected in a high diversity of functions with particular taxa performing specific tasks in food webs and nutrient cycling. The loss of functions which goes along with diversity loss can therefore be expected to destabilize ecosystems. Thus, with a random species loss, a higher variability of community traits may occur. In contrast, it is commonly assumed that there is a considerable degree of functional redundancy in soil food webs at the species level (Laakso and Setälä 1999; Wardle 1999; Cragg and Bardgett 2001). Rather, it is suggested that the effects of diversity of soil biota on belowground processes are driven by the functional dissimilarity and complementary among species groups consisting of functional similar species (Heemsbergen et al. 2004). Accordingly, Huhta et al. (1998) suggested that the diversity of functional groups has more predictable consequences for ecosystem functions than species diversity. However, as reviewed in Mikola et al. (2002), there are numerous studies highlighting species-specific impacts of soil animals on other soil biota and functions. Even within groups of soil biota, which may be considered as functionally uniform, species traits may crucially modify interacting effects in species mixtures (Postma-Blaauw et al. 2006). Moreover, Wolters (2001) pointed out three major arguments relativizing the suggested functional redundancy of soil animals. First, soil animal species differ in their functional importance so that random loss of species is much more likely to impact ecosystem functions than assumed by the redundancy hypothesis. Second, suggested redundant species might have functional significance by interacting with functionally important species. Third, the number of soil animal species needed to maintain ecosystem functioning might depend on the number of functions investigated.

Decomposer animals may have a multitude of influences on the function of an ecosystem, e.g., by their contribution to the decomposition process, alteration of soil structure, and interactions with other soil organisms (Scheu 2003; Wardle et al. 2004). This has been shown to translate into changes in the aboveground food web (Wurst and Jones 2003; Poveda et al. 2005) with synergistic effects of interactions between different decomposer taxa (Eisenhauer et al. 2010c). Accordingly, some decomposer species (e.g., earthworms) are known to importantly affect the activity of other soil taxa (Brown 1995; Eisenhauer et al. 
2007; Straube et al. 2009; Eisenhauer 2010). This, however, should lead to strong mixing effects but may not necessarily translate into higher variability within systems with the same mixtures of decomposer species. Thus, soil organism interactions and functional complementarity might be more important than generally assumed (Robinson et al. 1993; Eisenhauer et al. 2010c). However, it remains unclear if these beneficial impacts on mean productivity also enhance the stability of associated functions.

The impact of decomposers on communities is often related to their role in nutrient cycling and the increased availability of nutrients with decomposer activity. The impacts of decomposer diversity on the stability of ecosystem functions should depend on ecosystem characteristics like soil fertility and the nutrient demand of the plant community. Thus, the relative importance of decomposer fauna and its diversity may be weaker on fertile sites (Haase et al. 2008) and in plant communities characterized by high biological nitrogen fixation. Thus, anthropogenic impacts, such as land-use changes (e.g., application of fertilizers and changes in plant community composition), might not only affect the diversity of decomposers but probably also mask its stabilizing effects on ecosystem functions.

Here, we investigate the impacts of decomposer diversity on the stability (reliability) of three important aboveground and belowground ecosystem functions: primary productivity (shoot and root biomass), litter decomposition, and herbivore infestation. Therefore, we analyzed the results of three laboratory experiments manipulating decomposer diversity (1-3 species) in experimental grassland communities in terms of variability of the measured variables. We hypothesized that (1) decomposer diversity enhances the stability of ecosystem functions and (2) impacts depend on abiotic (fertilization) and biotic (plant community composition) factors with more pronounced impacts in low-fertility treatments (no fertilization, grass and herb communities) than in high-fertility treatments (high fertilization, legume communities).

\section{Materials and methods}

\section{Experiment 1}

Seeds of seven grass species (Alopecurus myosuroides Huds., Brachypodium pinnatum L., Briza media L., Bromus sterilis L., Echinochloa crus-galli L., Festuca ovina L., Poa annua L.) were sown into pots in the greenhouse. Day length was maintained at $12 \mathrm{~h}$ with supplementary light (sodium lamps, $400 \mathrm{~W}$; Philips Son-T Agro, Eindhoven, The Netherlands). Temperature varied between $15^{\circ} \mathrm{C}$ (night) and at maximum $25^{\circ} \mathrm{C}$ (day). After 3 weeks, one seedling of each grass species was planted into microcosms consisting of PVC tubes (inner diameter $10.4 \mathrm{~cm}$, height $20 \mathrm{~cm}$ ) closed with 100- $\mu \mathrm{m}$ nylon mesh at the bottom (see Haase et al. 2008). Each microcosm was equipped with a ring of transparent vitrification foil of $20 \mathrm{~cm}$ height to prevent the escape of soil animals. Soil was taken from an old fallow grassland site (Lahnberge near Marburg, Hesse, Germany; $50^{\circ} 48^{\prime} \mathrm{N}, 8^{\circ} 48^{\prime} \mathrm{E}, 325 \mathrm{~m}$ above sea level) and, prior to use, was defaunated by freezing at $-25^{\circ} \mathrm{C}$ for 7 days. After a further 7 days, three subsets of 501 of soil were irrigated by adding three times 101 of deionized water to each every 2 days to leach the nutrients which were released as a result of the defaunation process. The soil was mixed with sand ( $\mathrm{v} / \mathrm{v}$ ratio $1: 1)$, resulting in initial nutrient contents of $2.4 \mathrm{mg} \mathrm{NO}_{3}{ }^{-}$and $1.1 \mathrm{mg} \mathrm{NH}_{4}{ }^{+}$per kilogram soil (dry mass) (determined from pooled subsamples). Each microcosm was filled to a height of $6 \mathrm{~cm}$ with sand to facilitate drainage and with 11 of the soil-sand mixture. Five grams of litter material (swath, consisting mainly of grass leaves) were placed at the soil surface. Three levels of soil fertility were created by adding $0,0.2$ or $2 \mathrm{~g} / \mathrm{l}$ of a slowrelease NPK-fertilizer (Basacote Plus 3M, 16-8-12 NPK, coated with trace elements; Compo, Münster, Germany). Microcosms were watered every other day with $100 \mathrm{ml}$ of deionised water.

After 2 weeks, we added springtails, enchytraeids and earthworms separately and in every possible combination in addition to a decomposer-free control to the microcosms. For this, we used 40 individuals of Folsomia candida Willem (Collembola), $25 \mu \mathrm{g}$ of Enchytraeus albidus Henle (Enchytraeidae) and one individual of Lumbricus terrestris L. (Lumbricidae) [fresh weight with gut content $4.45 \pm$ $0.2 \mathrm{~g}$ (mean \pm standard error)], respectively. These decomposer taxa represent a functional gradient ranging from primary (earthworms) to secondary decomposers (springtails) with enchytraeids as intermediate type. The experiment was set up in a full-factorial design with three fertility treatments and eight decomposer treatments. Every treatment combination was replicated five times $(\Sigma 120$ microcosms). Replicates were randomly assigned to five blocks and randomized within the blocks every other week. After 9 weeks, above- and belowground plant material was harvested, dried at $60^{\circ} \mathrm{C}$ and weighed.

\section{Experiment 2}

The experiment was conducted in a temperature-controlled greenhouse (temperature $18 \pm 2{ }^{\circ} \mathrm{C}$, humidity $\sim 70 \%, 16 \mathrm{~h}$ illumination per day with light intensity varying between 450 and $650 \mu \mathrm{E} \mathrm{m}^{-2} \mathrm{~s}^{-1}$ depending on weather conditions). Microcosms were set up consisting of PVC tubes (inner diameter $10 \mathrm{~cm}$, height $20 \mathrm{~cm}$ ), which were sealed at the bottom by a 1-mm mesh to allow drainage of water 
but prevent Collembola from escaping. Additionally, a plastic barrier (height $10 \mathrm{~cm}$ ) was attached on top of each experimental container to prevent aboveground Collembola escape. All microcosms were filled with $1.5 \mathrm{~kg}$ (fresh weight) of sieved $(2 \mathrm{~mm})$ and homogenized soil (equivalent to $1.25 \mathrm{~kg}$ dry weight) to a height of $\sim 15 \mathrm{~cm}$. The soil (pH 8.1, carbon content $4.6 \%, \mathrm{C} / \mathrm{N}$ ratio 15.7) was taken from the south-eastern edge of the Jena Experiment field site and defaunated by freezing at $-22^{\circ} \mathrm{C}$ for 2 weeks. The Jena Experiment is a long-term grassland study investigating interactions between plant diversity and ecosystem processes and focussing on element cycling and trophic interactions. The site was formerly as typical Central European mesophilic grassland and the soil is Eutric Fluvisol. To leach nutrients from the soil which became available due to the defaunation process all microcosms were irrigated with $50 \mathrm{ml}$ of deionized water per day for 6 days prior to the start of the experiment.

Nine plant species belonging to three plant functional groups (grasses, herbs and legumes) were selected from the species pool of the Jena Experiment (Roscher et al. 2004) and pre-germinated to a height of $\sim 5 \mathrm{~cm}$ (for 3 weeks) from seeds obtained from a commercial supplier (RiegerHofmann, Blaufelden-Raboldshausen, Germany). Trays for pre-germination were filled with defaunated Jena soil in the greenhouse (for details on greenhouse conditions, see above).

Four seedlings of each grass (Lolium perenne L., Dactylis glomerata L., Phleum pratense L.), herb (Knautia arvensis L., Crepis biennis L., Centaurea jacea L.) and legume (Trifolium repens L., Trifolium pratense L., Medicago varia $\mathrm{L}$.) species were transplanted into the microcosms to establish three different plant functional group communities (grasses, herbs and legumes), each consisting of 12 plant individuals of one plant functional group.

After transplanting the seedlings, the microcosms were watered every second day $(50 \mathrm{ml}$ portions of deionized water) to ensure successful establishment of the plant communities and germinating weeds were removed for 14 days. Subsequently, 20 medium-sized adult individuals of each Folsomia candida Willem, Heteromurus nitidus Templeton and Protaphorura armata Gisin from laboratory cultures were added to the microcosms to establish the following Collembola treatments: one control treatment without Collembola, three single-species treatments, three two-species treatments, containing every possible twospecies mixture, and one three-species treatment, containing 20 individuals of each of the three Collembola species. Each treatment (three plant community treatments $\times$ eight Collembola diversity treatments $=24$ treatments) was replicated four times ( $\Sigma 96$ microcosms), and the pots were placed in the greenhouse and randomized every week to avoid edge effects caused by differences in light availability and humidity.

For simulation of natural conditions, to provide initial surface cover and to investigate litter decomposition, $3 \mathrm{~g}$ of dried litter material $\left(2.53 \% \mathrm{~N}, \mathrm{C} / \mathrm{N}\right.$ ratio 17.3 , dried at $60^{\circ} \mathrm{C}$ and cut into pieces of max. $3 \mathrm{~cm}$, collected near the field site of the Jena Experiment) consisting mainly of grass and herb leaves were placed on the soil surface after Collembola addition. Microcosms were irrigated daily with an increasing quantity of deionized water (initially $50 \mathrm{ml}$ every 2 days, after 10 weeks up to $150 \mathrm{ml}$ per day) according to the requirements of the growing plants. All microcosms received the same amount of water to avoid effects of different water availability.

After 15 weeks, the plant shoot biomass was harvested by cutting shoots at soil surface level, separated to species, dried at $60^{\circ} \mathrm{C}$ for 5 days, and weighed. Roots were washed using a 2-mm mesh, dried at $60^{\circ} \mathrm{C}$ for 5 days and weighed. Remaining litter material on the soil surface was sampled, dried $\left(60^{\circ} \mathrm{C}\right.$ for 5 days) and weighed.

\section{Experiment 3}

Microcosms were set up consisting of PVC tubes (inner diameter $10 \mathrm{~cm}$, height $25 \mathrm{~cm}$ ) covered by $1-\mathrm{mm}$ mesh at the bottom to prevent earthworms (Aporrectodea caliginosa Savigny and Lumbricus terrestris L.) from escaping but allowing water drainage. Additionally, a plastic barrier (10 cm height) prevented earthworms from escaping from experimental containers. The same soil was used as in "Experiment 2". A total of 48 microcosms each filled with $1.9 \mathrm{~kg}$ (dry weight, height of soil core $20 \mathrm{~cm}$ ) of sieved $(2 \mathrm{~mm})$, defaunated (dried at $50^{\circ} \mathrm{C}$ for 3 days) and homogenized soil were placed in a temperature-controlled greenhouse at a day/night regime of $16 / 8 \mathrm{~h}$ and $20 /$ $16 \pm 2{ }^{\circ} \mathrm{C}$. Before adding soil organisms and plants, the microcosms were watered regularly for 1 week $(50 \mathrm{ml}$ of deionized water every other day) to leach nutrients released as a result of the defaunation procedure and to adjust the gravimetric soil water content to about $20 \%$. Mixed grass litter material collected at the field site of the Jena Experiment was dried $\left(60^{\circ} \mathrm{C}, 3\right.$ days $)$ and cut into pieces of about $4 \mathrm{~mm}$.

The decomposer fungus Fusarium graminearum Schwabe was cultured on potato-dextrose-agar (PDA) at $4^{\circ} \mathrm{C}$. For Fusarium treatments, $60 \mathrm{~g}$ dried grass litter material was added to $900 \mathrm{ml}$ deionized water in Erlenmeyer flasks and autoclaved twice (each $20 \mathrm{~min}$ at $120^{\circ} \mathrm{C}$ ). For the inoculation of one of the Fusarium treatments with the fungus, a spore suspension was prepared by adding fungus-containing PDA blocks to one of the sterile Erlenmeyer flasks. Both suspensions (with and without $F$. graminearum) were kept at $20^{\circ} \mathrm{C}$ on a shaker 
for 4 weeks to ensure fungal growth and sporulation. Then, $13 \mathrm{~g}$ grass litter material (fresh weight) was added to each microcosm $10 \mathrm{~cm}$ below the soil surface to simulate the plowing of agricultural fields. Removal of Fusarium-infected material from the soil surface has been shown to decrease the infectious potential of this fungus (Oldenburg et al. 2008). Half the microcosms received decomposer fungus-infested litter material and the other half non-infested litter material to create treatments with and without microbial decomposers.

Two wheat seeds (Triticum aestivum L.; winter wheat, derived from Lochow-Petkus, Zuchtstation Wetze, Germany) were added to each microcosm and watered every second day with $50 \mathrm{ml}$ deionized water. After 6 days, redundant wheat seedlings were removed to start the experiment with one wheat individual of similar size per microcosm (height $\sim 10 \mathrm{~cm})$.

Then, four subadult individuals of $A$. caliginosa (total fresh weight with gut content $2.29 \pm 0.01 \mathrm{~g}$ ) as well as one subadult individual of $L$. terrestris (total fresh weight with gut content $3.94 \pm 0.11 \mathrm{~g}$ ) were each added to experimental microcosms to establish the following decomposer treatments: one control treatment without decomposers, three single-species treatments, three two-species treatments (all possible mixtures), and one three-species treatment. Each treatment (eight decomposer diversity treatments) was replicated six times ( $\Sigma 48$ microcosms). Earthworms had been extracted at the field site of the Jena Experiment using electro-shocking (Eisenhauer et al. 2009) 2 months before experimental setup and kept at $5^{\circ} \mathrm{C}$ in buckets filled with Jena soil.

The experiment lasted for 11 weeks and light intensity varied between 450 and $650 \mu \mathrm{E} \mathrm{m}^{-2} \mathrm{~s}^{-1}$ depending on weather conditions. Microcosms were irrigated four times a week with $50 \mathrm{ml}$ deionized water in weeks $1-3$ and with $100 \mathrm{ml}$ deionized water in weeks 4-11. Thereby, all microcosms received the same amount of water to avoid effects of different water availability. Microcosms were randomized every week. Two weeks after the addition of earthworms (start of the experiment) aphids (Rhopalosiphum padi L.; obtained from Katz Biotech, Baruth, Germany) were added to each wheat plant. We added three adult aphids to each of three wheat leaves (nine individuals per microcosm). Aphids could move freely on the plants of the microcosm they were added but also between plants of different microcosms.

The number of aphids per plant was determined after 5 weeks since leaves started withering. After 11 weeks, spikes and plant shoots were harvested separately by cutting spikes at their bases and shoots at soil surface level. Spike, shoot and root material were dried at $70^{\circ} \mathrm{C}$ for 3 days and weighed. When washing the roots, earthworms were collected by hand and weighed individually (fresh weight with gut content). Roots were washed using a sieve $(2 \mathrm{~mm})$, dried at $70^{\circ} \mathrm{C}$ for 3 days and weighed.

Calculations and statistical analysis

The coefficient of variation (CV) is a widely used measure of stability in ecological experiments (McCann 2000; Tilman et al. 2006; Weigelt et al. 2008). We used 'reliability' of an ecosystem function, i.e., the variability among replicate communities, as a measure of stability (Naeem and Li 1997; Flynn et al. 2008). Thus, we calculated the $\mathrm{CV}$ (standard deviation divided by the mean) from all replicates (Experiment 1: 5 replicates, Experiment 2: 4 replicates, and Experiment 3: 6 replicates) of a specific treatment for each of the three experiments separately. That means that the variability within one treatment served as the measure of stability. The higher the $\mathrm{CV}$, i.e., the variability, the lower is the reliability, i.e., the stability, of a specific treatment. In the following, we will only use the terms stability and variability. Means of primary productivity, litter decomposition and herbivore infestation in each decomposer treatment are given in Table 1; however, results will be discussed elsewhere (M. Schädler, unpublished data; A.C.W. Sabais, N. Eisenhauer, S. Scheu, unpublished data).

For each experiment, we thus obtained one $\mathrm{CV}$ for the control ( 0 decomposers), three $\mathrm{CVs}$ for the monocultures and 2-species mixtures, respectively, and one CV for the 3 -species mixtures. Then we performed one-sample $t$ tests in order to investigate if the CVs calculated for control treatments and 3-species mixtures differ significantly from the CVs calculated for monocultures and 2-species mixtures, respectively. Due to small sample sizes, this represents a very conservative test, and thus we also present distinct tendencies with $P \leq 0.1$. We did not correct for multiple statistical tests (e.g., the Bonferroni correction; Rice 1989) considering the mathematical and logical argumentation by Moran (2003). However, we accentuate that our approach increases the probability of achieving a significant result by chance. Statistical analyses were performed using STATISTICA 7.1 (StatSoft).

\section{Results}

\section{Experiment 1}

Impacts of decomposer richness on the stability of primary productivity showed different patterns at the three fertility levels. The stability of total biomass was significantly lower, i.e., the $\mathrm{CV}$ was significantly higher, in 3-species mixtures than in monocultures and 2-species mixtures in unfertilized plant communities (Fig. 1a). This was due to 
Table 1 Experiment 1: means in total biomass, shoot biomass and root biomass (all in $\mathrm{g}$ microcosm ${ }^{-1}$ ) per decomposer diversity level and fertilizer treatment; Experiment 2: means in total biomass, shoot biomass, root biomass (all in $\mathrm{g}$ microcosm ${ }^{-1}$ ) and litter decomposition (g remaining litter microcosm ${ }^{-1}$ ) per decomposer diversity level and plant community treatment; Experiment 3: means in total biomass, shoot biomass, root biomass and spike biomass (all in $\mathrm{g}$ wheat individual ${ }^{-1}$ ) and aphid infestation (aphids wheat individual ${ }^{-1}$ ) per decomposer diversity level

Experiment 1

\begin{tabular}{|c|c|c|c|c|c|c|c|c|c|c|c|c|}
\hline \multirow[b]{2}{*}{ Decomposer diversity } & \multicolumn{4}{|c|}{ Fertilizer level 0} & \multicolumn{4}{|c|}{ Fertilizer level 1} & \multicolumn{4}{|c|}{ Fertilizer level 2} \\
\hline & 0 & 1 & 2 & 3 & 0 & 1 & 2 & 3 & 0 & 1 & 2 & 3 \\
\hline Total biomass & 1.75 & 2.22 & 2.24 & 2.38 & 3.64 & 2.70 & 2.95 & 3.27 & 6.03 & 6.51 & 5.83 & 5.02 \\
\hline Shoot biomass & 1.37 & 1.69 & 1.73 & 1.92 & 2.91 & 2.05 & 2.22 & 2.48 & 4.65 & 5.37 & 4.66 & 4.04 \\
\hline Root biomass & 0.37 & 0.53 & 0.52 & 0.46 & 0.73 & 0.65 & 0.72 & 0.79 & 1.38 & 1.14 & 1.18 & 0.98 \\
\hline
\end{tabular}

Experiment 2

\begin{tabular}{|c|c|c|c|c|c|c|c|c|c|c|c|c|}
\hline \multirow[b]{2}{*}{ Decomposer diversity } & \multicolumn{4}{|c|}{ Grass community } & \multicolumn{4}{|c|}{ Herb community } & \multicolumn{4}{|c|}{ Legume community } \\
\hline & 0 & 1 & 2 & 3 & 0 & 1 & 2 & 3 & 0 & 1 & 2 & 3 \\
\hline Total biomass & 23.19 & 26.10 & 21.92 & 19.58 & 10.48 & 14.17 & 11.15 & 21.12 & 42.74 & 43.06 & 42.70 & 46.19 \\
\hline Shoot biomass & 3.05 & 3.64 & 3.50 & 3.56 & 2.72 & 3.23 & 2.79 & 3.94 & 21.11 & 22.70 & 23.33 & 23.51 \\
\hline Root biomass & 20.14 & 22.46 & 18.42 & 16.02 & 7.77 & 10.94 & 8.35 & 17.18 & 21.62 & 20.35 & 19.38 & 22.68 \\
\hline Litter decomp. & 0.67 & 0.54 & 0.71 & 0.94 & 0.76 & 0.97 & 1.10 & 1.06 & 0.78 & 1.12 & 1.50 & 1.23 \\
\hline
\end{tabular}

Experiment 3

\begin{tabular}{lcccc} 
& \multicolumn{2}{l}{ Winter wheat } \\
\cline { 2 - 5 } Decomposer diversity & 0 & 1 & 2 & 3 \\
\hline Total biomass & 0.94 & 1.18 & 1.48 & 1.16 \\
Shoot biomass & 0.62 & 0.73 & 0.87 & 0.76 \\
Root biomass & 0.06 & 0.10 & 0.16 & 0.11 \\
Spike biomass & 0.26 & 0.35 & 0.44 & 0.29 \\
Aphid infestation & 428 & 500 & 493 & 608 \\
\hline
\end{tabular}

the de-stabilizing effect of decomposer richness on shoot biomass (Fig. 1d), whereas root biomass remained unaffected (Fig. 1g). Similarly, the stability of total biomass was significantly lower in 3 -species mixtures than in the presence of low-diversity decomposer communities in highly fertilized plant communities (Fig. 1c). At this level of fertility, the de-stabilizing effect of decomposer richness was true for both shoot (Fig. 1f) and root biomass (Fig. 1i). By contrast, the stability of total biomass of moderate fertilized plant communities was not affected by decomposer richness (Fig. 1b). However, as indicated by the separate analysis of shoot and root biomass, the presence of one decomposer species had opposing impacts on the stability of shoot and root biomass. While the stability of shoot biomass was increased in decomposer monocultures compared to the control treatment (Fig. 1e), the stability of root biomass was decreased (Fig. 1h).

\section{Experiment 2}

Impacts of decomposer richness on the stability of primary productivity and litter decomposition depended on the type of plant community. Although the stability of total biomass (Fig. 2a) and root biomass (Fig. 2g) of grass communities was not affected significantly by decomposer richness, stability of shoot biomass increased significantly with increasing decomposer richness (Fig. 2d). By contrast, decomposer richness did not affect the stability of primary productivity in herb communities (Figs. 2b, e, h). However, the stability of total biomass in legume communities was higher in presence of one and two decomposers than in the control treatment (Fig. 2c). Thereby, shoot biomass was mainly stabilized by decomposer monocultures (Fig. 2f), while root biomass was more stable in presence of two decomposer species (Fig. 2i).

The direction of decomposer impacts on the stability of litter decomposition varied considerably between plant communities. While the stability of litter decomposition increased with decomposer richness in grass communities (Fig. 2j), it decreased significantly in herb communities (Fig. 2k). By contrast, the control treatment in legume communities and the one containing three decomposers were more stable in litter decomposition than decomposer monocultures (Fig. 21). 
Fig. 1 Stability of plant productivity in Experiment 1. Coefficient of variation $(\mathrm{CV})$ of a-c total biomass, $\mathbf{d}-\mathbf{f}$ shoot biomass, and $\mathbf{g}-\mathbf{i}$ root biomass as affected by decomposer richness (0-3 species) and fertilization (level 0-2).

Asterisks indicate significant differences between the control (decomposer richness 0) and decomposer richness levels 1 and 2, respectively, as well as between decomposer richness level 3 and decomposer richness levels 1 and 2, respectively (one-sample $t$ test). Means with standard error. $(*) P<0.1$, $* P<0.05, * * P<0.01$
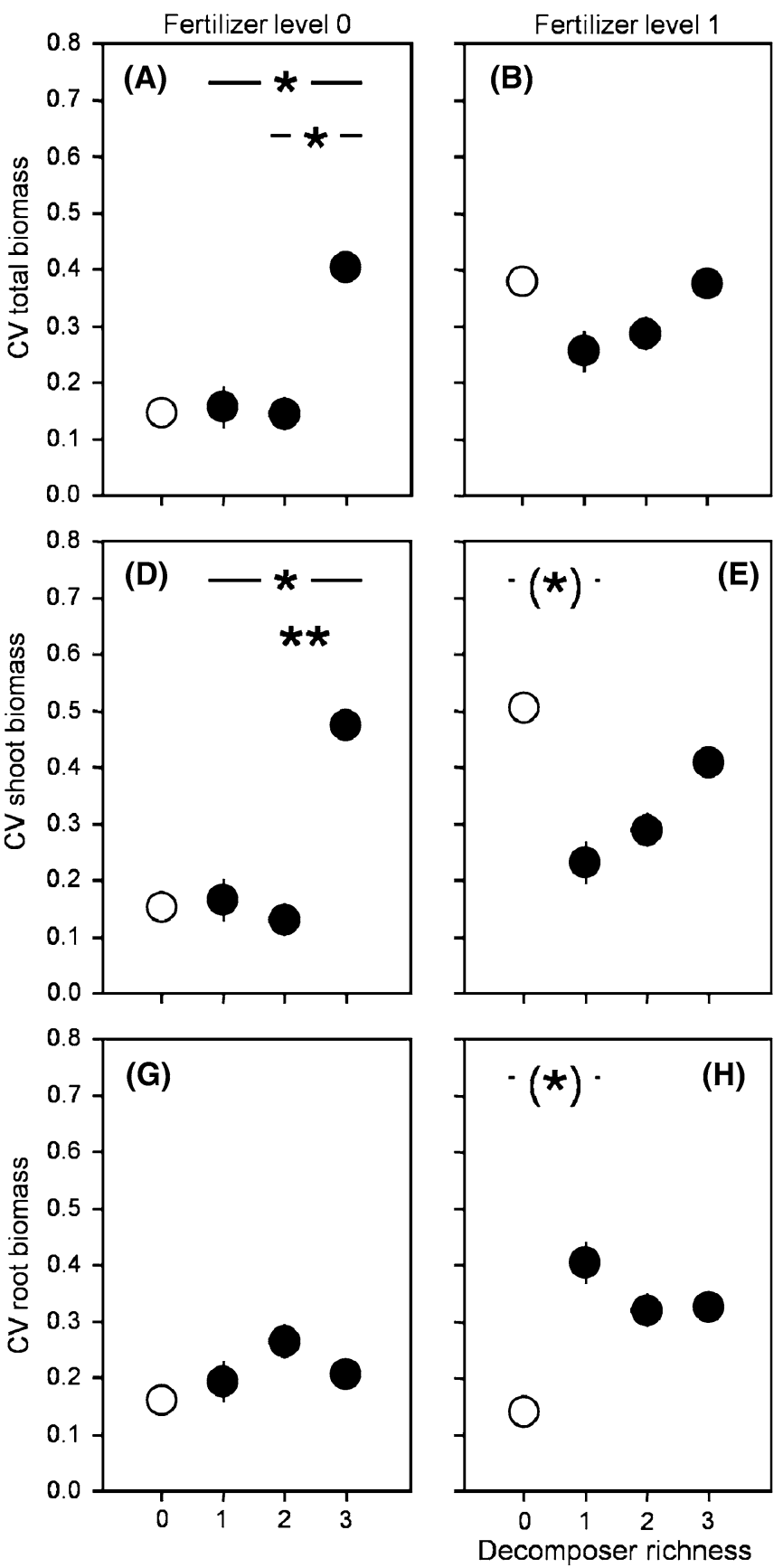

Fertilizer level 2
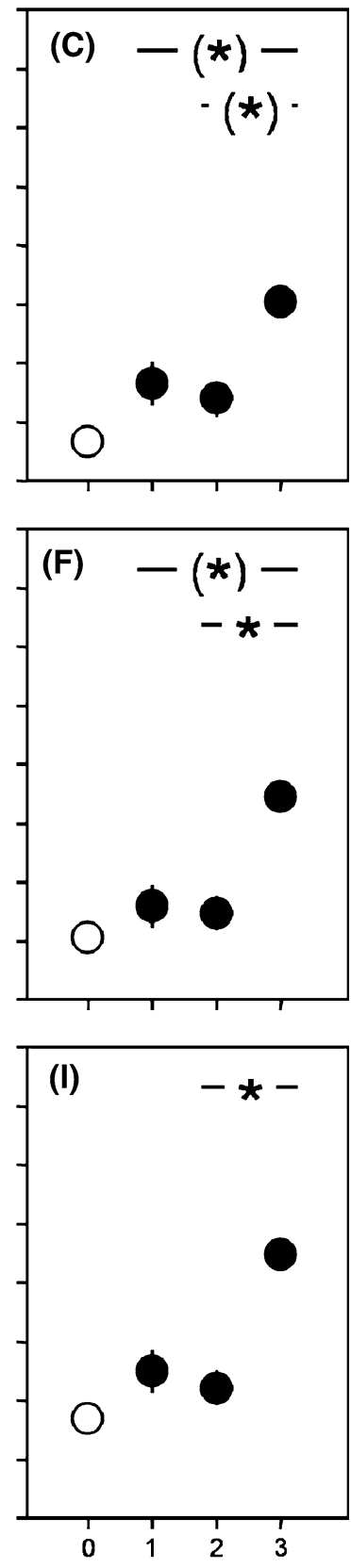

\section{Experiment 3}

Decomposer richness had a destabilizing impact on primary productivity but a stabilizing one on aphid infestation. The stability of total biomass was lower in the presence of three decomposers than in decomposer monocultures (Fig. 3a). This was consistently true for the stability of shoot (Fig. 3b), root (Fig. 3c), and spike biomass (Fig. 3d). However, the stability of aphid infestation was significantly higher in the presence of three decomposers than in treatments with one and two decomposers, respectively (Fig. 3e).

\section{Discussion}

Impacts of decomposer diversity on ecosystem stability

Decomposer diversity significantly affected the stability of all aboveground and belowground ecosystem functions investigated in the present study. Nevertheless, these results partly contradict both hypotheses formulated in the introduction. First, we expected decomposer diversity to enhance the stability of ecosystem functions due to more pronounced and constant effects (complementarity of decomposer species). The results, however, indicate 
Fig. 2 Stability of plant productivity and decomposition in Experiment 2. Coefficient of variation $(\mathrm{CV})$ of $\mathbf{a}-\mathbf{c}$ total biomass, $\mathbf{d}-\mathbf{f}$ shoot biomass, $\mathbf{g}-\mathbf{i}$ root biomass, and $\mathbf{j}-\mathbf{l}$ litter decomposition as affected by decomposer richness $(0-3$ species) and plant community (grass community, herb community, and legume community). Asterisks indicate significant differences between the control (decomposer richness 0 ) and decomposer richness levels 1 and 2,

respectively, as well as between decomposer richness level 3 and decomposer richness levels 1 and 2, respectively (one-sample $t$ test). Means with standard error. $\left({ }^{*}\right) P<0.1, * P<0.05$, $* * P<0.01$
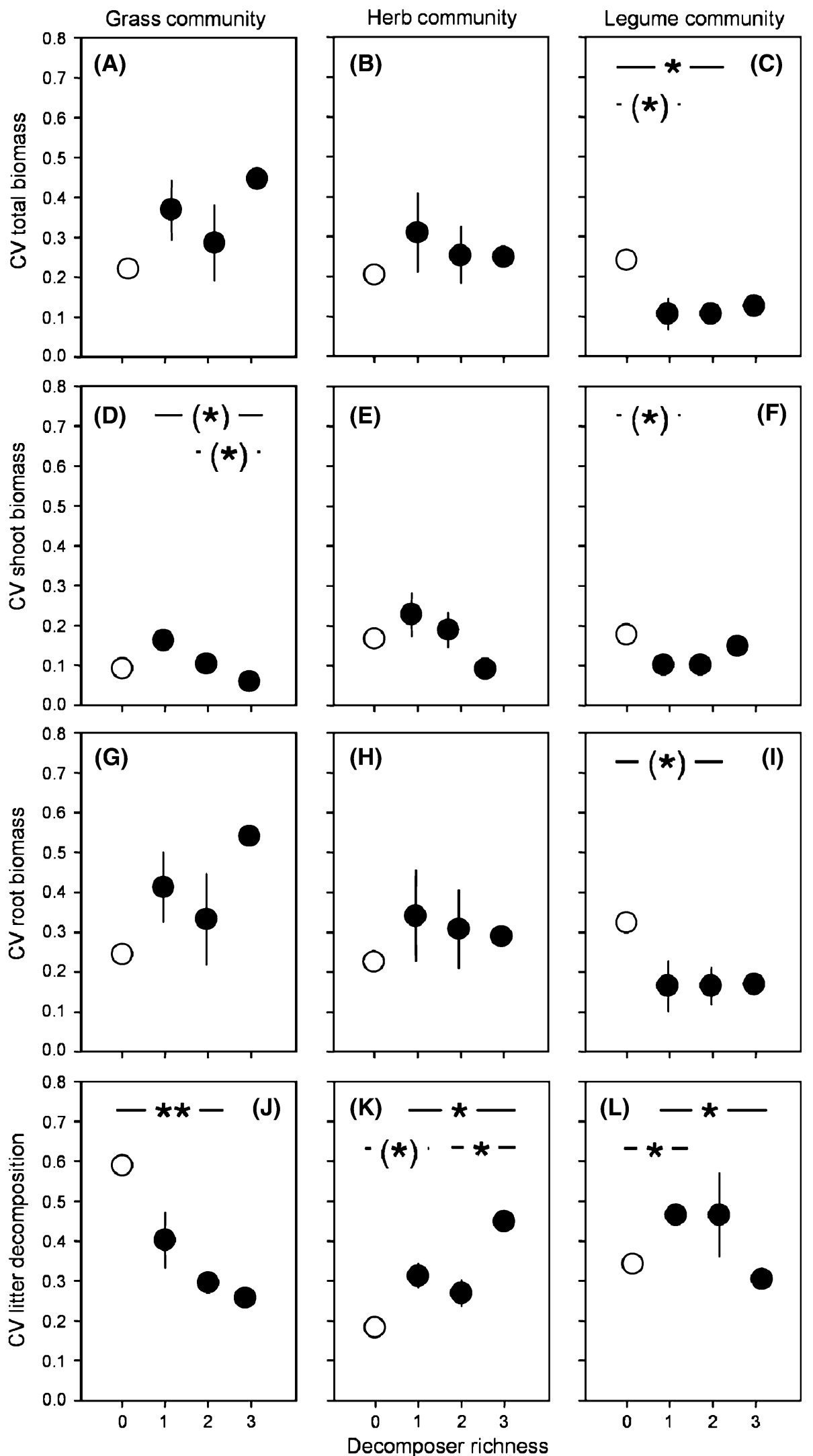

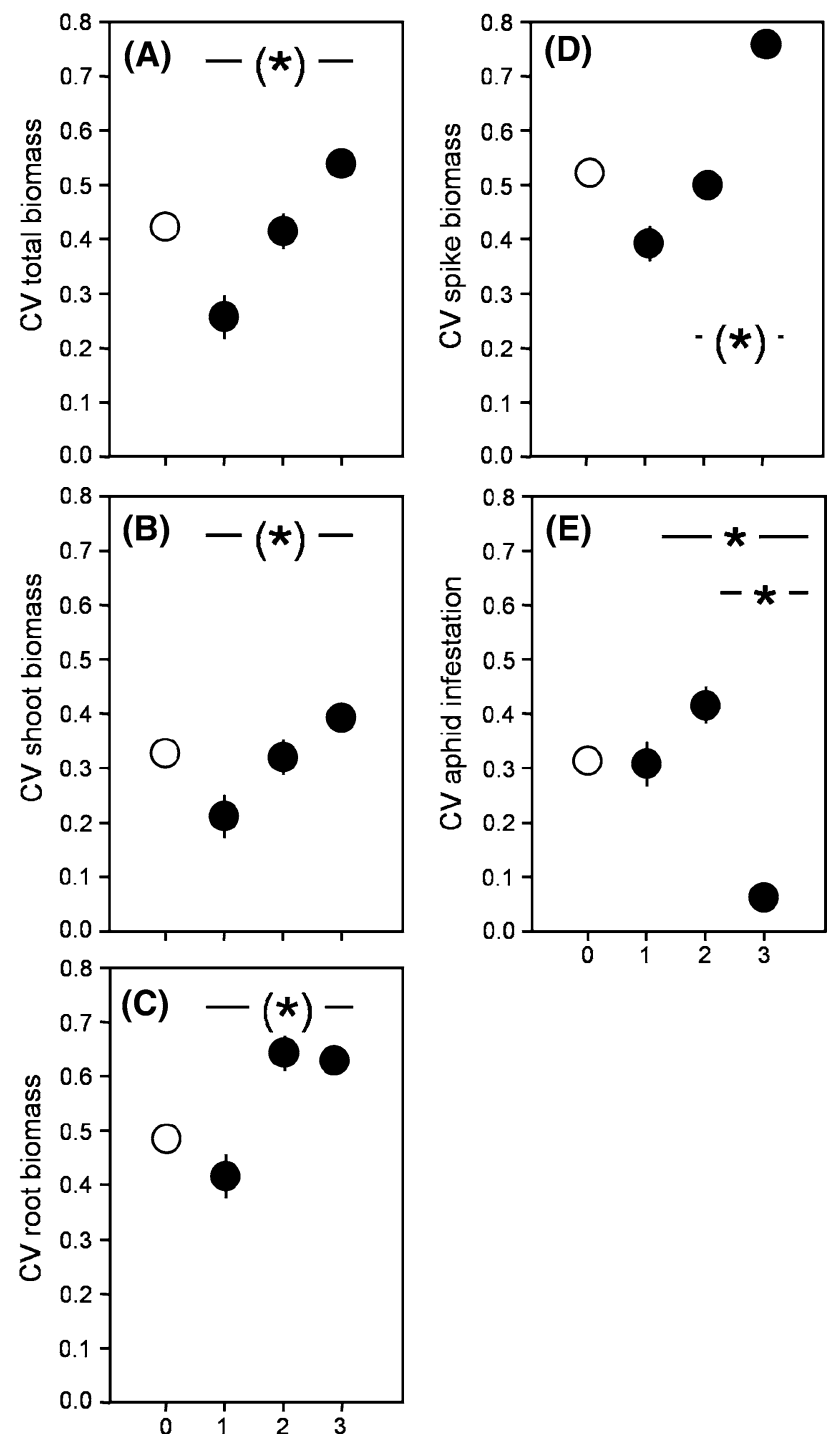

Fig. 3 Stability of plant productivity and herbivore infestation in Experiment 3. Coefficient of variation (CV) of a total biomass, b shoot biomass, c root biomass, d spike biomass, and e aphid infestation as affected by decomposer richness (0-3 species). Asterisks indicate significant differences between the control (decomposer richness 0 ) and decomposer richness levels 1 and 2, respectively, as well as between decomposer richness level 3 and decomposer richness levels 1 and 2, respectively (one-sample $t$ test). Means with standard error. $(*) P<0.1,{ }^{*} P<0.05$

inconsistent impacts of decomposer diversity on the stability of functions. While primary productivity mainly was destabilized (Exp. 1 and 3), litter decomposition (Exp. 2) and aphid infestation (Exp. 3) were essentially stabilized by increasing decomposer diversity. Moreover, we hypothesized that impacts depend on abiotic (fertilization) and biotic (plant community composition) factors with more pronounced impacts in low-fertility treatments (no fertilization, grass and herb communities) than in high-fertility treatments (high fertilization, legume communities). Again, the results did not follow our expectations as impacts of decomposer diversity on the stability of primary productivity did not differ between unfertilized and highly fertilized treatments (Exp. 1), and since stabilizing effects of decomposer diversity were even more pronounced in legume communities than in grass and herb communities (Exp. 2). However, most importantly, this study for the first time indicates that decomposer diversity indeed impacts the stability of essential aboveground and belowground ecosystem functions of several trophic levels, exceeding the importance of effects of plant community assembly and fertilization.

Remarkably, not only diversity of functionally different decomposer species affected ecosystem stability (Exp. 1 and 3) but also the diversity of supposed very similar decomposer species, i.e., different Collembola species, impacted the stability of primary productivity and particularly that of litter decomposition (Exp. 2). These results are in great contrast to the widespread assumption of belowground redundancy (Laakso and Setälä 1999; Wardle 1999). However, it should be noted that there was only a weak trend toward higher stability of primary productivity in communities affected by a functionally more similar decomposer community (Exp. 2). This is in accordance with the findings of Cragg and Bardgett (2001), which demonstrated varying effects of different Collembola species with rather idiosyncratic responses of decomposition dynamics to mixing of species. The present study, however, extends the observation of inconsistent responses of decomposition by showing that the process was stabilized in grass and legume communities but destabilized in herb communities. This implicates that impacts of decomposers on the stability of essential ecosystem functions might depend on plant community assembly. Moreover, Exp. 2 shows that the effects of decomposer richness on the stability of plant communities do not necessarily follow the patterns of impacts on stability of decomposition rate. Accordingly, Exp. 3 indicates that effects of decomposer richness on the stability of herbivore infestation did also not follow the patterns of impacts on the stability of primary productivity. Thus, inconsistent impacts complicate the estimation of consequences of belowground diversity loss.

Underpinning mechanisms

Generally, we expected that mechanisms already discussed for effects of plant diversity on the stability of primary productivity (reviewed in McCann 2000) might also apply for impacts of decomposer diversity. Particularly, interactions between and functional complementarity of different decomposers (Heemsbergen et al. 2004; Eisenhauer et al. 2010c) should lead to more pronounced and constant 
effects on ecosystem processes, thereby increasing their stability. We expected decomposer diversity to enhance the stability of several ecosystem functions, i.e., primary productivity, litter decomposition, and herbivore infestation, since belowground positive interactions in the decomposition process (Robinson et al. 1993) were recently reported to impact ecosystem functions over several trophic levels in a synergistic way (Eisenhauer et al. 2010c). Indeed, decomposer presence stabilized primary productivity of legume communities and decomposer diversity that of litter decomposition in grass and legume communities (Exp. 2), and herbivore infestation of wheat plants (Exp. 3). Surprisingly, surface litter decomposition was highest in decomposer (Collembola) monocultures (Table 1; A.C.W. Sabais, N. Eisenhauer, S. Scheu, unpublished data). Although Collembola are known to feed on a wide spectrum of food sources, including bacteria, fungi, algae, plant litter, living plant tissue and animals, fungi are regarded as the most important food source (Chen et al. 1995; Klironomos and Kendrick 1995; Hopkin 1997). However, stable isotope analysis revealed that Collembola diversity increased the decomposition of ${ }^{15} \mathrm{~N}$ labeled root litter material (not shown; A.C.W. Sabais, N. Eisenhauer, S. Scheu, unpublished data), suggesting that Collembola indeed accelerated the decomposition of soil organic matter but not of surface litter. Nonetheless, decomposer diversity thereby likely increased nutrient availability for plants (as indicated by elevated ${ }^{15} \mathrm{~N}$ signatures in plant shoot tissue) resulting in an enhanced stability of primary productivity in legume communities. Collembola were reported to affect the competition between soil microorganisms and plants for nutrients (Partsch et al. 2006), which might have benefited legumes in Exp. 2. Nevertheless, these explanations have to be treated with caution since the proposed mechanisms did not apply for the stability of primary productivity of grass communities and litter decomposition in herb communities, which, in contrast to that in the above-mentioned grass and legume communities, was even destabilized by decomposer diversity. The broad spectrum of food sources and context-dependent food switching might be responsible for these inconsistent impacts; however, this topic deserves further attention, e.g., by exploring the mechanisms via stable isotope analysis. In fact, results of a recent field study underline the relevance of Collembola density and diversity for plant community assembly and performance (Eisenhauer et al. 2010b).

Remarkably, the stability of aphid infestation was significantly higher in the most diverse decomposer treatments than in monocultures or two-species mixtures (Exp. 3). This suggests that decomposer diversity impacts the stability of higher trophic levels and propagates to the aboveground food web. In a similar laboratory experiment, Eisenhauer et al. (2010c) found that complementarity of decomposers in the decomposition process presumably synergistically enhanced nutrient availability for plants and aphids, resulting in over-additive effects of decomposer richness on herbivore performance. Moreover, $\mathrm{Ke}$ and Scheu (2008) reported that impacts of decomposers on aphid reproduction were due to the mobilization of particularly litter $\mathrm{N}$ (not soil $\mathrm{N}$ ) as indicated by stable isotope analysis. Thus, probably the more constant (in space and time) and elevated nutrient supply via complementarity in decomposition also increased the stability of herbivore infestation in Exp. 3.

Primary productivity was mostly destabilized by decomposer diversity (Exp. 1 and 3). Two major mechanisms might be responsible which probably acted simultaneously. First, in both experiments, the anecic earthworm species L. terrestris was used (Bouché 1977). This species forms few permanent vertical burrows and feeds on surface litter. Thereby, L. terrestris creates "hot-spots" of nutrient availability and microbial activity (Brown 1995) and thus significantly contributes to the spatial heterogeneity of soils (Maraun et al. 1999; Eisenhauer et al. 2008). Patchy distribution due to the action of this anecic earthworm species has been reported for nutrients (reviewed in Brown 1995), microorganisms (Brown 1995; Maraun et al. 1999), soil microarthropods (Hamilton and Sillman 1989; Maraun et al. 1999), and weed seedlings (Milcu et al. 2006a; Eisenhauer et al. 2008). Thus, one explanation for destabilizing effects might be the elevated probability to include L. terrestris in the decomposer community with increasing decomposer diversity (sampling or selection effect; Huston 1997). Inspecting the two-species mixtures in more detail supported our suggestion by showing that mixtures including $L$. terrestris were more variable than mixtures without this species (in 67 and 100\% the cases in Exp. 1 and 3, respectively; not shown). This destabilizing effect is in accordance with a recent field study indicating that L. terrestris decreased the stability of grassland communities against plant invasion (Eisenhauer et al. 2008). However, it should be considered that destabilizing effects of L. terrestris might depend on the scale investigated as destabilizing effects on the local scale might be stabilizing on a broader scale. Additionally, the significant role of L. terrestris might have been due to simple biomass effects, since earthworm biomass exceeded the biomass of the other decomposer species used in the analyzed experiments by far. However, as earthworms usually dominate the biomass of invertebrates in non-acidic soils (Coleman et al. 2004), the experimental setup likely reflected natural conditions.

Second, decomposers might have competed for resources as reported by Milcu et al. (2006b) for experimental grassland communities. Belowground competitive interactions might therefore be responsible for the decreased 
stability of primary productivity due to reduced availability and patchy distribution of nutrients for plants. This suggestion underlines the complexity of belowground interactions and species composition effects (Mikola and Setälä 1998; Dauber and Wolters 2000; Cragg and Bardgett 2001).

Impacts of decomposer diversity were expected to be most apparent in low-fertility treatments as fertilizer application might mask decomposer effects (Haase et al. 2008). This hypothesis was not supported by the present study as impacts were rather inconsistent. Most likely, decomposers not only affect ecosystem functions via their action in the decomposition process but also by directly interacting with plant roots (Scheu 2003; Endlweber 2007), and by changing the structure and functioning of the soil microbial community (Scheu 2003; Partsch et al. 2006) and other soil animals (Brown 1995; Eisenhauer 2010). Thus, impacts of decomposer diversity on ecosystem stability most likely depend on various belowground interactions that complicate simple conclusions. This is in accordance with the prediction derived from a modeling approach by de Ruiter et al. (1998) that varying interactions between soil biota differently affects ecosystem stability.

\section{Consequences of belowground diversity loss}

The intensive discussion on the importance of biodiversity for the stability of essential processes has prompted a multitude of studies since the middle of the last century (MacArthur 1955; Elton 1958). Nevertheless, research was extremely biased focusing mainly on the stability of primary productivity in aquatic and terrestrial ecosystems. Recent reviews undoubtedly highlighted the pronounced interrelationships between the aboveground and belowground subsystems in terrestrial ecosystems (Wardle et al. 2004; Bardgett et al. 2005) calling for the simultaneous investigation of both subsystems. The present study underlines the need for more holistic studies by indicating that belowground biodiversity loss might significantly impact the stability of various ecosystem functions. As above- and belowground biodiversity loss might be interlinked (Hooper et al. 2000; de Deyn and van der Putten 2005), soil feedback mechanisms are most likely to contribute to changes in the magnitude and stability of ecosystem functions.

The present study certainly has drawbacks, e.g., artificial laboratory experiments with unknown applicability to more natural systems, rather simple decomposer assemblages of three species at most (Mikola et al. 2002), and a low number of $\mathrm{CV}$ replicates per decomposer richness level. Moreover, very precise estimates of variance require large sample sizes (see examples in Krebs 1999) which exceed the number of replicates usually used in experiments.
However, the large list of significant effects of decomposer diversity on the stability of ecosystem functions opens a new field in ecological research by calling for more holistic studies on this topic. Particularly, the observation that decomposer diversity affected the stability of processes in all three laboratory experiments points to a general pattern rather than to experimental artefacts. Moreover, our study considers only one measure of stability: reliability. It might be hypothesized that decomposer richness may affect other measures like resilience, resistance and robustness without effects on the variability of a system which is not affected by disturbances. Further, it might be necessary to consider and explore the scale-dependency of effects of decomposer diversity (de Deyn and van der Putten 2005).

To summarize, inconsistent impacts of decomposer diversity on the stability of essential ecosystem functions were indicated to differ between plant communities of varying composition and fertility implicating that humaninduced changes of biodiversity and land-use management might have unpredictable effects on the processes mankind relies on. This study therefore points to the need of also considering soil feedback mechanisms in order to gain a comprehensive and holistic understanding of the impacts of current global change phenomena on the stability of essential ecosystem functions.

Acknowledgments We thank Stefan Scheu, Theodora Volovei, Casper M.U. Pusch, Andreas Lindfeld, Christian Schellhorn and Alexander C.W. Sabais for their help during the experiments. Two of the experiments were conducted in the framework of the Jena Experiment which is funded by the German Science Foundation (FOR 456). N. Eisenhauer acknowledges funding by the DFG (German Science Foundation; Ei 862/1-1).

Open Access This article is distributed under the terms of the Creative Commons Attribution Noncommercial License which permits any noncommercial use, distribution, and reproduction in any medium, provided the original author(s) and source are credited.

\section{References}

Balvanera P, Pfisterer AB, Buchmann N, He JS, Nakashizuka T, Raffaelli D, Schmid B (2006) Quantifying the evidence for biodiversity effects on ecosystem functioning and services. Ecol Lett 9:1146-1156

Bardgett RD, Cook R (1998) Functional aspects of soil animal diversity in agricultural grasslands. Appl Soil Ecol 10:263-276

Bardgett RD, Bowman WD, Kaufmann R, Schmidt SK (2005) A temporal approach to linking aboveground and belowground ecology. Trends Ecol Evol 20:634-641

Berlow E (1999) Strong effects of weak interactions in ecological communities. Nature 398:330-334

Bouché MB (1977) Strategies lombriciennes. In: Lohm U, Persson T (eds) Soil organisms as components of ecosystems. Ecological Bulletins 25. Stockholm, Sweden, pp 122-132

Brose U (2008) Complex food webs prevent competitive exclusion among producer species. Proc R Soc Lond B 275:2507-2514 
Brown GG (1995) How do earthworms affect microfloral and faunal community diversity? Plant Soil 170:209-231

Chen B, Snider RJ, Snider RM (1995) Food preference and effects of food type on the life history of some soil Collembola. Pedobiologia 39:496-505

Coleman DC, Crossley DA Jr, Hendrix PF (2004) Fundamentals of soil ecology, 2nd edn. Elsevier, San Diego

Cragg RG, Bardgett RD (2001) How changes in soil fauna diversity and composition within a trophic group influence decomposition processes. Soil Biol Biochem 33:2073-2081

Dauber J, Wolters V (2000) Microbial activity and functional diversity in the mounds of three different ant species. Soil Biol Biochem 32:93-99

De Deyn GB, van der Putten WH (2005) Linking aboveground and belowground diversity. Trends Ecol Evol 20:625-633

De Deyn GB, Raaijmakers CE, Zoomer HR, Berg MP, de Ruiter PC, Verhoef HA, Bezemer TM, van der Putten WH (2003) Soil invertebrate fauna enhances grassland succession and diversity. Nature 422:711-713

De Ruiter PC, Neutel A-M, Moore JC (1998) Biodiversity in soil ecosystems: the role of energy flow and community stability. Appl Soil Ecol 10:217-228

Eisenhauer N (2010) The action of an animal ecosystem engineer: identification of the main mechanisms of earthworm impacts on soil microarthropods. Pedobiologia. doi:10.1016/j.pedobi.2010. 04.003

Eisenhauer N, Scheu S (2008) Invasibility of experimental grassland communities: the role of earthworms, plant functional group identity and seed size. Oikos 117:1026-1036

Eisenhauer N, Partsch S, Parkinson D, Scheu S (2007) Invasion of a deciduous forest by earthworms: changes in soil chemistry, microflora, microarthropods and vegetation. Soil Biol Biochem 39:1099-1110

Eisenhauer N, Milcu A, Sabais ACW, Scheu S (2008) Animal ecosystem engineers modulate the diversity-invasibility relationship. PLoS ONE 3:e3489

Eisenhauer N, Milcu A, Sabais ACW, Scheu S (2009) Earthworm and belowground competition effects on plant productivity. Oecologia 161:291-301

Eisenhauer N, Sabais ACW, Schonert F, Scheu S (2010a) Soil arthropods beneficially rather than detrimentally impact plant performance in experimental grassland systems of different diversity. Soil Biol Biochem 42:1418-1424

Eisenhauer N, Ackermann M, Gass S, Klier M, Migunova V, Nitschke N, Ruess L, Sabais ACW, Weisser WW, Scheu S (2010b) Nematicide impacts on nematodes and feedbacks on plant productivity in a plant diversity gradient. Acta Oecol $36: 477-483$

Eisenhauer N, Hörsch V, Moeser J, Scheu S (2010c) Synergistic effects of microbial and animal decomposers on plant and herbivore performance. Basic Appl Ecol 11:23-34

Elton CS (1958) The ecology of invasions by animals and plants. Methuen, London

Endlweber K (2007) Decomposer-plant interactions: Effects of Collemnola on plant performance and competitiveness. PhD thesis, Darmstadt University of Technology, Darmstadt, Germany

Fargione JE, Tilman D (2005) Diversity decreases invasion via both sampling and complementarity effects. Ecol Lett 8:604-611

Flynn DFB, Schmid B, He J-S, Wolfe-Bellin KS, Bazzaz FA (2008) Hierarchical reliability in experimental plant assemblages. J Plant Ecol 1:59-65

Haase J, Brandl R, Scheu S, Schädler M (2008) Above- and belowground interactions are mediated by nutrient availability. Ecology 89:3072-3081
Hamilton WE, Sillman DY (1989) Influence of earthworm middens on the distribution of soil microarthropods. Biol Fertil Soils 8:279-284

Heemsbergen DA, Berg MP, Loreau M, van Hal JR, Faber JH, Verhoef HA (2004) Biodiversity effects on soil processes explained by interspecific functional dissimilarity. Science 306:1019-1020

Hooper DU, Bignell DE, Brown VK, Brussard L, Dangerfield JM, Wall DH, Wardle DA, Coleman DC, Giller KE, Lavelle P, van der Putten WH, de Ruiter PC, Rusek J, Silver WL, Tiedje JM, Wolters V (2000) Interactions between aboveground and belowground biodiversity in terrestrial ecosystems: patterns, mechanisms, and feedbacks. Bioscience 50:1049-1061

Hopkin SP (1997) Biology of the springtails, insecta: Collembola. Oxford University Press, Oxford

Huhta V, Persson T, Setälä H (1998) Functional implications of soil fauna diversity in boreal forests. Appl Soil Ecol 10:277-288

Huston MA (1997) Hidden treatments in ecological experiments: reevaluating the ecosystem function of biodiversity. Oecologia 108:449-460

Ke X, Scheu S (2008) Earthworms, Collembola and residue management change wheat (Triticum aestivum) and herbivore pest performance (Aphidina: Rhopalosiphum padi). Oecologia 157:603-617

Klironomos JN, Kendrick B (1995) Relationships among microarthropods, fungi, and their environment. Plant Soil 170:183-197

Krebs C (1999) Ecological methodology. Benjamin/Cummings, Menlo Park

Laakso J, Setälä H (1999) Sensitivity of primary production to changes in the architecture of belowground food webs. Oikos 87:57-64

MacArthur RH (1955) Fluctuations of animal populations and a measure of community stability. Ecology 36:533-536

Maraun M, Alphei J, Bonkowski M, Buryn R, Migge S, Peter M, Schaefer M, Scheu S (1999) Middens of the earthworm Lumbricus terrestris (Lumbricidae): microhabitats for microand mesofauna in forest soil. Pedobiologia 43:276-287

McCann KS (2000) The diversity-stability debate. Nature 405:228-233

Mikola J, Setälä H (1998) Relating species diversity to ecosystem functioning-mechanistic backgrounds and experimental approach with a decomposer food web. Oikos 83:180-194

Mikola J, Bardgett RD, Hedlund K (2002) Biodiversity, ecosystem functioning and soil decomposer food webs. In: Loreau $\mathrm{M}$, Naeem S, Inchausti $\mathrm{P}$ (eds) Biodiversity and ecosystem functioning: synthesis and perspectives. Oxford University Press, Oxford, pp 169-180

Milcu A, Schumacher J, Scheu S (2006a) Earthworms (Lumbricus terrestris) affect plant seedling recruitment and microhabitat heterogeneity. Funct Ecol 20:261-268

Milcu A, Partsch S, Langel R, Scheu S (2006b) The response of decomposers (earthworms, springtails and microorganisms) to variations in species and functional group diversity of plants. Oikos 112:513-524

Moran DM (2003) Arguments for rejecting the sequential Bonferroni in ecological studies. Oikos 100:403-405

Mulder CPH, Uliassi DD, Doak DF (2001) Physical stress and diversity-productivity relationships: the role of positive interactions. Proc Natl Acad Sci USA 98:6704-6708

Naeem S, Li S (1997) Biodiversity enhances ecosystem reliability. Nature 390:507-509

Oldenburg E, Kramer S, Schrader S, Weinert J (2008) Impact of the earthworm Lumbricus terrestris on the degradation of Fusariuminfected and deoxynivalenol-contaminated wheat straw. Soil Biol Biochem 40:3049-3053 
Partsch S, Milcu A, Scheu S (2006) Decomposers (Lumbricidae, Collembola) affect plant performance in model grasslands of different diversity. Ecology 87:2548-2558

Postma-Blaauw MB, Bloem J, Faber JH, van Groenigen JW, de Goede RGM, Brussaard L (2006) Earthworm species composition affects the soil bacterial community and net nitrogen mineralization. Pedobiologia 50:243-256

Poveda K, Steffan-Dewenter I, Scheu S, Tscharnke T (2005) Effects of decomposers and herbivores on plant performance and aboveground plant-insect interactions. Oikos 108:503-510

Raffaelli DG, van der Heijden M, van der Putten W, Kennedy E, Koricheva J, Lacroix G, Mikola J, Persson L, Petchey O, Wardle DA (2002) Multi-trophic processes and ecosystem function. In: Loreau M, Naeem S, Inchausti P (eds) Biodiversity and ecosystem functioning. Oxford University Press, Oxford, pp 147-154

Rice WR (1989) Analyzing tables of statistical tests. Evolution 43:223-225

Robinson CH, Dighton J, Frankland JC, Coward PA (1993) Nutrient and carbon dioxide release by interacting species of strawdecomposing fungi. Plant Soil 151:139-142

Roscher C, Schumacher J, Baade J, Wilcke W, Gleixner G, Weisser WW, Schmid B, Schulze E-D (2004) The role of biodiversity for element cycling and trophic interactions: an experimental approach in a grassland community. Basic Appl Ecol 5: 107-121

Schädler M, Jung G, Brandl R, Auge H (2004) Secondary succession is influenced by belowground insect herbivory on a productive site. Oecologia 138:242-252
Scheu S (2003) Effects of earthworms on plant growth: patterns and perspectives. Pedobiologia 47:1-11

Straube D, Johnson EA, Parkinson D, Scheu S, Eisenhauer N (2009) Nonlinearity of effects of invasive ecosystem engineers on abiotic soil properties and soil biota. Oikos 118:885-896

Tilman D, Downing JA (1994) Biodiversity and stability in grasslands. Nature 367:363-365

Tilman D, Reich P, Knops JMH (2006) Biodiversity and ecosystem stability in a decade-long grassland experiment. Nature 441:629-632

Van der Heijden MGA, Bardgett RD, van Straalen NM (2008) The unseen majority: soil microbes as drivers of plant diversity and productivity in terrestrial ecosystems. Ecol Lett 11:296-310

Wardle DA (1999) How soil food webs make plants grow. Trends Ecol Evol 14:418-420

Wardle DA, Bardgett RD, Klironomos JN, Setälä H, van der Putten WH, Wall DH (2004) Ecological linkages between aboveground and belowground biota. Science 304:1629-1633

Weigelt A, Schumacher J, Roscher C, Schmid B (2008) Does biodiversity increase spatial stability in plant community biomass. Ecol Lett 11:338-347

Wolters V (2001) Biodiversity of soil animals and its function. Eur J Soil Biol 37:221-227

Wurst S, Jones TH (2003) Indirect effects of earthworms (Aporrectodea caliginosa) on an above-ground tritrophic interaction. Pedobiologia 47:91-97

Yachi S, Loreau M (1999) Biodiversity and ecosystem functioning in a fluctuating environment: the insurance hypothesis. Proc Natl Acad Sci USA 96:1463-1468 